\title{
Outpatient- and inpatient-based buckling surgery: a comparative study
}

This article was published in the following Dove Press journal:

Clinical Ophthalmology

25 April 2014

Number of times this article has been viewed

\section{Jin Cheol Lee*}

Yu Cheol Kim*

Department of Ophthalmology, Keimyung University School of Medicine, Dongsan Medical Center, Daegu, Korea

*Both authors contributed equally to this work
Correspondence: Yu Cheol Kim Department of Ophthalmology, Keimyung University School of Medicine, Dongsan Medical Center, 56, Dalseong-ro, Jung-gu, Daegu, 700-712, Republic of Korea

$\mathrm{Tel}+82532508026$

Fax +82 532507705

Email eyedr@dsmc.or.kr
Purpose: To evaluate the clinical outcomes of ambulatory buckling surgery, comparing outpatient- with inpatient-based surgery.

Methods: The authors performed a retrospective study of 80 consecutive cases of rhegmato genous retinal detachment from January 2009 to December 2011 treated by scleral buckling surgery. Two groups of patients were defined according to inpatient (group 1) or outpatient (group 2) surgery, and a comparison of several parameters between these two groups was performed. Results: Of the 80 subjects in this study, the average age of group 1 ( 50 patients) was 49.7 years, and that of group 2 (30 patients) was 47.5 years. There were no statistically significant differences in the average logarithm of the minimum angle of resolution-visual acuity, the condition of the lens, or the presence of retinal lattice degeneration prior to the surgery between the groups. There were no statistically significant differences in the patterns of tear or retinal detachment or in surgical procedure between the groups. Comparing the best-corrected visual acuity after 6 months with that prior to the surgery, the changes in group 1 and group 2 were 0.26 and 0.31 , respectively. The functional success rates of group 1 and group 2 after 6 months were $90 \%$ and $93 \%$, respectively, and the anatomical success rates of group 1 and group 2 after 6 months were $94 \%$ and $96 \%$, respectively, but these were also statistically insignificant.

Conclusion: Hospitalization is not essential for buckling surgery in uncomplicated rhegmatogenous retinal detachment surgery.

Keywords: ambulatory, scleral buckling, rhegmatogenous retinal detachment

\section{Introduction}

The duration of hospital stay for surgical patients has reduced over the years, with a rise in day surgery having made a significant contribution. ${ }^{1}$ Not only is outpatient surgery economical, but it gives the patients mental security and psychological stability, which may lead to faster recovery. ${ }^{2}$ The tendency is stronger in ophthalmology than other departments, because the general condition is relatively stable. For instance, in the past, most cataract operations required a hospitalization period, but 1-day surgery is common these days. These changes were made not only by the development of medical technologies that allowed less invasive procedures, but also by reevaluating medical considerations about excessive treatments or admissions that might have been customary but unsubstantiated.

Retinal detachment is separation of the sensory retina layer from the retinal pigment epithelium layer; rhegmatogenous retinal detachment (RRD) is the most frequent form. Buckling or pars plana vitrectomy are common procedures for treatment of RRD, with anatomical success rates of $79 \%-93 \%{ }^{3-6}$ 
Formerly, patients were generally hospitalized for postoperative positional stabilization and recovery from general anesthesia in the buckling procedure; however, there is not enough evidence to support positional stabilization, and the development of other procedures and anesthetic agents has made general anesthesia unnecessary.

Therefore, we evaluated the clinical outcomes of ambulatory buckling surgery, comparing outpatient- with inpatientbased surgery.

\section{Materials and methods}

From January 2009 to December 2011, 80 consecutive patients who were diagnosed with RRD and able to be followed up for more than 6 months after scleral buckling in Keimyung University, Dongsan Medical Center were included in this study. Fifty hospitalized patients were defined as group 1, and 30 patients who underwent 1-day surgery without admission were defined as group 2. All buckling surgeries were performed on the day when the RRD was diagnosed. In principle, patients were hospitalized for surgery; outpatient-based surgeries were performed only when a bed was not available. Patients who had other retina lesions, such as retinal vascular disease or macular degeneration, grade C proliferative vitreoretinopathy, or a history of treatment for retinal detachment or breaks, as well as those with planned elective buckling surgeries, were excluded.

The buckling surgeries were performed under retrobulbar anesthesia by two ophthalmologists. After localization of retinal break with indirect ophthalmoscopy, a silicone sponge was placed using a 5-0 Dacron (Alcon Surgical Inc., Fort Worth, TX, USA) or Ethibond Excel ${ }^{\circledR}$ polyester suture (Ethicon Inc., Somerville, NJ, USA). External drainage of subretinal fluid was followed. When buckle height was insufficient, sulfur hexafluoride (SF6) gas was injected into the vitreous cavity at the end of the operation and the patients were positioned postoperatively so that the bubble was in contact with the retinal break, and the retinal break was flattened against the sclera buckle. ${ }^{7}$ The next day, demarcation photocoagulation laser was applied, instead of intraoperative cryotherapy.

After surgery, inpatients had bed rest, except for toileting and meals, and they were discharged 2 days after surgery. Outpatients went home after surgery, rested, and visited the hospital the next day.

Best-corrected visual acuity (BCVA), slit-lamp biomicroscopy, intraocular pressure, and funduscopy were evaluated preoperatively and postoperatively at 1 day, 1 week, and
1, 3, and 6 months. Visual acuity was measured by Snellen chart and then converted to logMAR acuity.

Anatomical and functional success were evaluated at postoperative 6-month follow-up. Anatomical success was defined as macular attachment and no aggravation of retinal detachment on optical coherence tomography and fundus examination. The criteria of functional success were that the BCVA was over $20 / 40$ or improved by more than two lines in the Snellen chart; if the preoperative BCVA was less than $20 / 200$, functional success was defined as improvement of more than one step: for example, when visual acuity was improved from light perception to hand movement, hand movement to finger count, or finger count to above 0.1 . When additional surgery was required for the treatment of RRD, it was considered a fail anatomically and functionally.

Statistical analysis was calculated using SPSS software (version 17.0; IBM Corporation, Armonk, NY, USA). The independent $t$-test and Pearson's chi-square test were used for comparison of two groups. Null hypotheses of no difference were rejected if $P$-values were less than 0.05 .

\section{Results}

The mean age of group 1 (50 cases) was 49.7 years and that of group 2 (30 cases) was 47.5 years. There were no statistically significant differences between the two groups in preoperative $\log$ MAR visual acuity each of 0.41 (group 1), 0.40 (group 2), lens condition, or peripheral retinal lattice degeneration (Table 1 ). There were also no statistically significant differences in retinal break type or aspect of retinal detachment between group 1 and group 2 (Table 2).

During the surgical procedure, there were no statistically significant differences in size of the silicone sponge or intravitreous SF6 gas injection during scleral buckling (Table 3).

The changes between BCVA preoperatively and at 6 months postoperatively were 0.26 (group 1) and 0.31 (group 2), respectively; and not significantly different, although group 2 had a higher score. Six months after the surgery, the functional

Table I Preoperative demographics and clinical data of inpatients (group I) and outpatients (group 2)

\begin{tabular}{llll}
\hline & Group I & Group 2 & P-value \\
\hline Age (years) & $49.7 \pm 7.56^{\mathrm{a}}$ & $47.5 \pm 4.39^{\mathrm{a}}$ & $0.120^{\mathrm{b}}$ \\
Sex (male/female) & $25 / 25$ & $16 / 14$ & $0.773^{\mathrm{c}}$ \\
Preoperative BCVA (logMAR) & $0.4 \mathrm{I}$ & 0.40 & $0.08^{\mathrm{b}}$ \\
Phakia/pseudophakia (n) & $4 \mathrm{I} / 9$ & $26 / 4$ & $0.584^{\mathrm{c}}$ \\
Peripheral degeneration (n) & 17 & 8 & $0.493^{\mathrm{c}}$ \\
\hline
\end{tabular}

Notes: a ${ }^{D}$ ata are presented as mean \pm standard deviation; ' analyzed with independent $t$-test; 'analyzed with Pearson's chi-square test.

Abbreviations: BCVA, best-corrected visual acuity; $\log M A R$, logarithm of the minimum angle of resolution; $\mathrm{n}$, number. 
Table 2 Break types and extent of retinal detachment in inpatients (group I) and outpatients (group 2)

\begin{tabular}{llll}
\hline Break type & $\begin{array}{l}\text { Group I } \\
\text { (n) }\end{array}$ & $\begin{array}{l}\text { Group 2 } \\
\text { (n) }\end{array}$ & P-value $^{\text {a }}$ \\
\hline Multiple breaks & 19 & 9 & 0.468 \\
$\leq$ I quadrant detachment & 32 & 16 & 0.346 \\
I $<, \leq 2$ quadrant detachment & 13 & 12 & 0.191 \\
$>2$ quadrant detachment & 5 & 2 & 0.648 \\
Marked vitreous traction & 15 & 7 & 0.518 \\
Large breaks (>3.0 disc diameter) & 16 & 5 & 0.131 \\
\hline
\end{tabular}

Note: aAnalyzed with Pearson's chi-square test.

success rates were $90 \%$ (group 1) and $93 \%$ (group 2), and the anatomical success rates were $94 \%$ (group 1) and 96\% (group 2). There was no significant difference in functional success rate and anatomical success rate between the two groups (Table 4). There were no statistically significant differences in anatomical and functional success rates or in visual prognosis between inpatient and outpatient buckling surgery.

\section{Discussion}

As medical technologies develop, not only final outcome but also convenience and expedience of the treatment are considered important, and unnecessary or excessive bed rest, postures, and hospital stay are regarded as overtreatment. ${ }^{1}$ Medical recommendations about posture, rest, and hospitalization are being researched, with some being described as excessive and exaggerated. ${ }^{2}$ For example, absolute bed rest and bilateral patching with head elevation were the standard care of traumatic hyphema in the past. One study has suggested that bilateral patching and bed rest might decrease rebleeding in patients with traumatic hyphema; ${ }^{8}$ on the other hand, no benefit to the prevention of rebleeding has been proved by hospitalization or enforced bed rest. ${ }^{9-12}$ In macular hole treatment, there is controversy about postoperative facedown posture and its duration. ${ }^{13}$

Retinal detachment has a position-dependent pathophysiology, which means that the severity and the progression
Table 4 Postoperative clinical data of inpatients (group I) and outpatients (group 2)

\begin{tabular}{|c|c|c|c|}
\hline & Group I & Group 2 & $P$-value \\
\hline $\begin{array}{l}\text { Change between VA } \\
\text { preoperatively and at } 3 \text { months } \\
\text { postoperatively (logMAR) }\end{array}$ & 0.26 & 0.32 & $0.778^{\mathrm{a}}$ \\
\hline $\begin{array}{l}\text { Change between VA } \\
\text { preoperatively and at } 6 \text { months } \\
\text { postoperatively (logMAR) }\end{array}$ & 0.26 & 0.31 & $0.742^{\mathrm{a}}$ \\
\hline Functional success rate (\%) & $90(45 / 50)$ & $93(28 / 30)$ & $0.609^{b}$ \\
\hline Anatomical success rate (\%) & $94(47 / 50)$ & $96(29 / 30)$ & $0.596^{\mathrm{b}}$ \\
\hline
\end{tabular}

Notes: ${ }^{2}$ Analyzed with independent $t$-test; banalyzed with Pearson's chi-square test. Abbreviations: VA, visual acuity; $\log M A R$, logarithm of the minimum angle of resolution.

of the disease are dependent on the location of the retinal tear. ${ }^{14,15}$ Therefore, attempts to estimate the location of a retinal tear from the shape of retinal detachment, or the severity or progression of the disease from the position prior to the surgery, have been made. ${ }^{15,16}$ Barr reported that the patients who had bed rest and a binocular patch prior to a surgical intervention showed a better surgical outcome among patients with retinal detachment of similar severity. ${ }^{17}$ Nevertheless, previous studies dealt mostly with pretreatments of a surgical intervention, ${ }^{17}$ and there is a lack of evidence supporting any therapeutic positions or periods of bed rest following a surgical intervention. In general, ambulation to the bathroom and normal diet are allowed on the following day of scleral buckling, but bed rest for the first 2-3 days is recommended in practice. Patients are usually hospitalized for 4-5 days after surgery, with 2-4 weeks of recuperation recommended after discharge. The patients are advised to return to daily living after 6 weeks.

Controversy also remains regarding postoperative position. Some insist that a position that faces the tear upwards is the best, because subretinal fluid should be further away from the tear, while some say that a position leading to the tear facing downwards is the best, in order to minimize the effect from the gravity; still others maintain that resting in

Table 3 Operative methods and sponge types used in inpatients (group I) and outpatients (group 2)

\begin{tabular}{|c|c|c|c|c|}
\hline Operative method & $\begin{array}{l}\text { Sponge size } \\
\text { (mm) }\end{array}$ & $\begin{array}{l}\text { Group I } \\
\text { (n) }\end{array}$ & $\begin{array}{l}\text { Group } 2 \\
\text { (n) }\end{array}$ & $P$-value ${ }^{a}$ \\
\hline \multirow[t]{2}{*}{ Segmental circumferential buckling only } & 3 & 23 & 14 & 0.945 \\
\hline & $3 \times 5$ & 5 & 4 & 0.648 \\
\hline Radial buckling only & 4 & 11 & 7 & 0.890 \\
\hline \multirow{2}{*}{$\begin{array}{l}\text { Segmental circumferential buckling + intravitreal sulfur } \\
\text { hexafluoridegas injection }\end{array}$} & 3 & 6 & 3 & 0.748 \\
\hline & $3 \times 5$ & 4 & 2 & 0.826 \\
\hline Radial buckling + intravitreal sulfur hexafluoridegas injection & 4 & I & 0 & 0.436 \\
\hline Total & & 50 & 30 & \\
\hline
\end{tabular}

Note: aAnalyzed with Pearson's chi-square test. 
supine position is sufficient. ${ }^{18,19}$ It remains unclear whether there is an optimal position or if an optimal position is truly necessary.

Considering the pathogenesis of retinal detachment, minimal mobilization minimizes the instability of the damaged retina and prevents further progression of the disease, ${ }^{2,20,21}$ however, it is unreasonable to think that the level of ambulation will affect the surgical outcome after the retinal tear is already repaired. Strict immobilization post-surgery might be an overzealous approach.

This study evaluated the need for hospitalization and bed rest immediately after scleral buckling in patients with retinal detachment. The patients were categorized into two groups: the patients who had bed rest in the hospital (group 1) and the patients who recuperated at home (group 2).

There were no statistically significant differences in the characteristics of the patients in each group prior to the surgery, such as age, sex, and visual acuity, or in the severity of retinal detachment or the size or number of tears. Moreover, there were no statistically significant differences in the changes between BCVA preoperatively and at 6 months postoperatively or in functional and anatomical success rates between the groups. In fact, it was group 2 that showed more improved eyesight and better anatomical and functional success rates, with slight but insignificant differences.

Relatively mild retinal detachment is treated in the outpatient department in some hospitals, but patients undergoing surgery due to retinal detachment in Keimyung University, Dongsan Medical Center were considered inpatients and were admitted to the hospital, rather than hospitalization being decided depending on the severity of retinal detachment or convenience. Outpatient-based surgeries were only performed if there were unavoidable logistical problems in the hospital.

This study has a statistical limitation. The working hypothesis was that there is no difference, while, logically, what an author must do is disprove the hypothesis that there is a difference. Unfortunately, lack of a difference can occur for many reasons, including a simple lack of statistical power. In addition, this study did not have enough patients for a noninferiority study, even with a $\pm 10 \%$ significance level. Group 2, however, was not inferior to group 1 at a $\pm 15 \%$ statistical significance level. The research power of the study is not strong due to its retrospective nature and small sample size. Further prospective, noninferior, randomized clinical trials should be conducted to increase the research power and confirm whether hospitalization is necessary for buckling surgery or not.

\section{Conclusion}

Hospitalization after scleral buckling for retinal detachment does not have a significant effect on visual acuity after the surgery or on the surgical success rate. Therefore, hospitalization is not essential for buckling surgery in uncomplicated RRD surgery.

\section{Disclosure}

The authors report no conflicts of interest in this work. A summary of this article was presented in part during the poster session of the 8th International Symposium of Ophthalmology-Hong Kong in December 2012.

\section{References}

1. Houghton K. Enhanced recovery and day surgery: the ultimate partners for elective surgery. The Journal of One Day Surgery. 2010; 20(4):92.

2. Skues M. The ultimate partners for elective surgery. The Journal of One Day Surgery. 2011;22:14-15.

3. Burton TC. Preoperative factors influencing anatomic success rates following retinal detachment surgery. Trans Sect Ophthalmol Am Acad Ophthalmol Otolaryngol. 1977;83(3 Pt 1):OP499-OP505.

4. Tani P, Robertson DM, Langworthy A. Prognosis for central vision and anatomic reattachment in rhegmatogenous retinal detachment with macula detached. Am J Ophthalmol. 1981;92(5):611-620.

5. Haritoglou C, Brandlhuber U, Kampik A, Priglinger SG. Anatomic success of scleral buckling for rhegmatogenous retinal detachment a retrospective study of 524 cases. Ophthalmologica. 2010;224(5): 312-318.

6. McPherson AR, O'Malley RE, Butner RW, Beltangady SS. Visual acuity after surgery for retinal detachment with macular involvement. Ann Ophthalmol. 1982;14(7):639-645.

7. Norton EW. Intraocular gas in the management of selected retinal detachments. Trans Am Acad Ophthalmol Otolaryngol. 1973;77(2): OP85-OP98.

8. Darr JL, Passmore JW. Management of traumatic hyphema. Am J Ophthalmol. 1967;63(1):134-136.

9. Read J, Goldberg MF. Comparison of medical treatment for traumatic hyphema. Trans Am Acad Ophthalmol Otolaryngol. 1974;78:OP799-OP815.

10. Kennedy RH, Brubaker RF. Traumatic hyphema in a defined population. Am J Ophthalmol. 1988;106(2):123-130.

11. Wright KW, Sunalp M, Urrea P. Bed rest versus activity ad lib in the treatment of small hyphemas. Ann Ophthalmol. 1988;20(4): $143-145$.

12. Edwards WC, Layden WE. Monocular versus binocular patching in traumatic hyphema. Am J Ophthalmol. 1973;76(3):359-362.

13. Chandra A, Charteris DG, Yorston D. Posturing after macular hole surgery: a review. Ophthalmologica. 2011;226 Suppl 1:3-9.

14. Park JM, Shim HS, Bae JH. A clinical study on rhegmatogenous retinal detachment. J Korean Ophthalmol Soc. 1993;34(11):1154-1161. Korean.

15. Sharma T, Challa JK, Ravishankar KV, Murugesan R. Scleral buckling for retinal detachment. Predictors for anatomic failure. Retina. 1994;14(4):338-343. 
16. Kaufman PL. Prognosis of primary rhegmatogenous retinal detachments. 2. Accounting for and predicting final visual acuity in surgically reattached cases. Acta Ophthalmol (Copenh). 1976;54(1):61-74.

17. Chang SD, Kim IT. Long-term visual recovery after scleral buckling procedure of rhegmatogenous retinal detachment involving the macula. Korean J Ophthalmol. 2000;14(1):20-26.

18. Barr CC. The histopathology of successful retinal reattachment. Retina. 1990;10(3):189-194.
19. Benson SE, Schlottmann PG, Bunce C, Xing W, Charteris DG. Optical coherence tomography analysis of the macula after scleral buckle surgery for retinal detachment. Ophthalmology. 2007;114(1):108-112.

20. Machemer R. Experimental retinal detachment in the owl monkey. IV. The reattached retina. Am J Ophthalmol. 1968;66(6):1075-1091.

21. Aaberg TM, Machemer R. Correlation of naturally occurring detachments with long-term retinal detachment in the owl monkey. Am J Ophthalmol. 1970;69(4):640-650.

\section{Publish your work in this journal}

Clinical Ophthalmology is an international, peer-reviewed journal covering all subspecialties within ophthalmology. Key topics include: Optometry; Visual science; Pharmacology and drug therapy in eye diseases; Basic Sciences; Primary and Secondary eye care; Patien Safety and Quality of Care Improvements. This journal is indexed on

Submit your manuscript here: http://www.dovepress.com/clinical-ophthalmology-journal

\section{Dovepress}

PubMed Central and CAS, and is the official journal of The Society of Clinical Ophthalmology (SCO). The manuscript management system is completely online and includes a very quick and fair peer-review system, which is all easy to use. Visit http://www.dovepress.com/ testimonials.php to read real quotes from published authors. 